\title{
Usage Potential of Sawdust as a Forest Industry Waste For Treatment of Colored Effluents
}

\author{
Fatih Deniz \\ Harran University, Dept. of Environmental Protection Technologies, Sanliurfa, Turkey
}

\begin{abstract}
In the present study, the usage potential of sawdust as a forest industry waste was evaluated for the treatment of colored industrial effluents containing Fast Green FCF synthetic dye. The effects of various environmental variables such as $\mathrm{pH}$, biosorbent amount, synthetic dye concentration and contact time on the dye removal ability of biosorbent material were studied in batch operating conditions. The kinetic and equilibrium studies were performed to elucidate the dye biosorption behavior of biosorbent. The synthetic dye biosorption capacity of biosorbent was highly affected by the environmental conditions. The kinetic and equilibrium studies showed that Elovich and Langmuir models were the best models for the elucidation of dye removal behavior of biosorbent. Based on Langmuir model, the maximum monolayer biosorption capacity under the optimum environmental conditions was estimated to be 26.834 $\mathrm{mg} \mathrm{g}^{-1}$. The obtained results revealed that the forest industry waste biomass used has usage potential for the treatment of synthetic dye pollution in aquatic environments.
\end{abstract}

Key words: Forest industry waste, Sawdust, Colored effluents, Biotreatment

\section{Introduction}

Water pollution has become a serious environmental issue due to mainly anthropogenic activities in recent years. Industrial wastewaters include harmful contaminants such as synthetic dyes, heavy metals and nutrients. Among the pollutant sources, dye substances are widely employed as coloring agents for the final products in various industrial branches like forest, textile, paper, food and leather industries. During the dyeing process, it is estimated that considerable percentages of dyes used $(10-15 \%)$ remain in unfixed forms in process waters and therefore huge volumes of colored industrial effluents are generated. Synthetic dyes are generally complex aromatic molecular structured organic compounds and are considered to be one of the main stable contaminant sources causing severe deleterious effects to biota $[1,2]$. Thus, before being discharged into receiving water systems, the elimination of these colorant substances from effluents is a primary issue for the dye handling industries. In the present study, the sawdust as a forest industry waste biomass was explored as a sustainable green generation alternative biosorbent source for the treatment of colored aqueous effluents. To test the wastewater cleaning ability of biosorbent, Fast Green FCF was selected as a common harmful model synthetic dye. The kinetic, equilibrium and thermodynamic studies were performed to elucidate the dye biosorption behavior of biosorbent.

*Corresponding author: Address: Harran University, Dept. of Environmental Protection Technologies, Sanliurfa, Turkey. E-mail address: f_deniz@ outlook.com, Phone: +90 4143183000 


\section{Materials and Method}

\subsection{Preparation of biosorbent material}

The waste sawdust biomass of Pinus brutia Ten. tree was collected from a local sawmill (Gaziantep, Turkey). The waste biomaterial was washed with tap water, followed by several washings with double distilled water to remove extraneous materials. It was dried in an oven until a constant weight was achieved. The material was crushed in a laboratory grinder, sieved through a $0.5 \mathrm{~mm}$ standard sieve and then modified CTAB chemical $\left(0.1 \mathrm{~mol} \mathrm{~L}^{-1}\right)$. The obtained final product was kept in a glass bottle for the biosorption assays.

\subsection{Preparation of model synthetic dye solution}

Fast Green FCF was used as a model synthetic dye pollutant and was supplied from Merck. A stock solution of dye $\left(1 \mathrm{~g} \mathrm{~L}^{-1}\right)$ was prepared by dissolving required amount of the dye in $1 \mathrm{~L}$ of distilled water. The working concentration of dye in the simulated colored solution was prepared by diluting the dye stock solution with distilled water.

\subsection{Dye treatment study}

Biosorption experiments were conducted by a set of conical flasks containing $100 \mathrm{~mL}$ of model synthetic dye solutions using the batch experiment technique. The flasks were agitated at a constant speed of $150 \mathrm{rpm}$ using an orbital shaker for the desired contact times at room temperature. Afterwards, nearly 1-2 mL of aqueous sample was collected from the experiment medium and centrifuged. The synthetic dye concentrations in the samples were measured by a UV-visible spectrophotometer at a wavelength of $625 \mathrm{~nm}$. The amount of dye biosorbed by the biosorbent $\left(q_{\mathrm{t}}\right.$, $\mathrm{mg} \mathrm{g}^{-1}$ ) was determined using the following mass balance equation:

$$
q_{\mathrm{t}}=\frac{\left(C_{0}-C_{\mathrm{t}}\right) V}{M}
$$

where $C_{0}$ and $C_{\mathrm{t}}\left(\mathrm{mg} \mathrm{L}^{-1}\right)$ are the concentrations of synthetic dye at the initial, and a $t$ time, respectively. $V(\mathrm{~L})$ is the volume of aqueous solution and $M(\mathrm{~g})$ is the mass of biosorbent.

\subsection{Modeling of dye biosorption system}

The biosorption kinetic data were modeled using the pseudo-first-order, pseudo-second-order, Elovich and intra-particle diffusion kinetic models. The experimental biosorption equilibrium data were modeled by the isotherm models of Freundlich, Langmuir and Dubinin-Radushkevich.

\section{Results and Discussion}

\subsection{Effect of contact time}

Fig. 1 indicates the influence of contact time on the dye biosorption process. The dye biosorption 
capacity of biosorbent increased over time and later remained almost constant. The higher dye biosorption at the initial stage may be explained by the presence of high concentration gradient and high accessibility of a large number of vacant sites on the surface of biosorbent. The slow biosorption rate at late stage may be attributed to the saturation of active sites and the increase in the repulsive forces between dye molecules on the biosorbent and in the biosorption medium [3, 4]. Based on the obtained results, it was determined that the optimum contact time was around $6 \mathrm{~h}$.

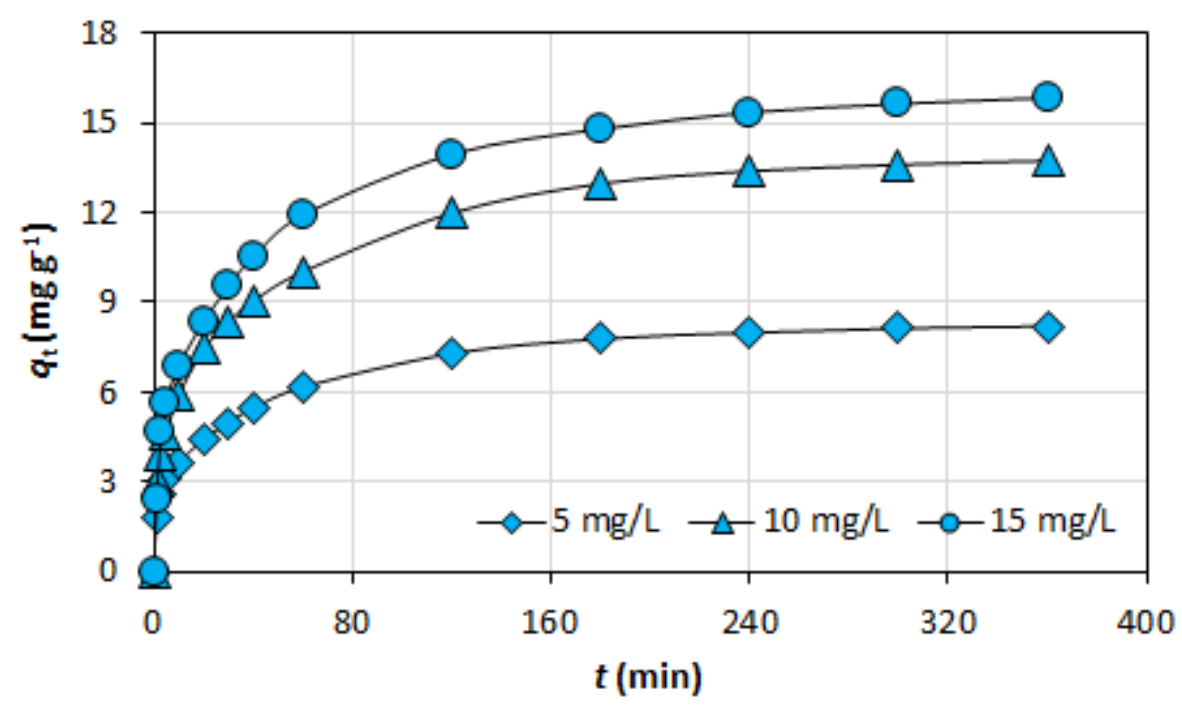

Fig. 1. Effect of contact time

\subsection{Effect of $\mathrm{pH}$}

Fig. 2 shows the effect of $\mathrm{pH}$ on the biosorption process. The dye removal decreased with an increase in the solution $\mathrm{pH}$. Since the surface charge of biosorbent is positive at lower $\mathrm{pH}$, the electrostatic attraction between the dye anion and the positively charged active biosorption sites on the surface of biosorbent leads to an increase in the dye removal. In contrast, at higher $\mathrm{pH}$, the biosorbent surface has a negative charge leading to decrease the anionic dye biotreatment due to electrostatic repulsion forces [5]. 


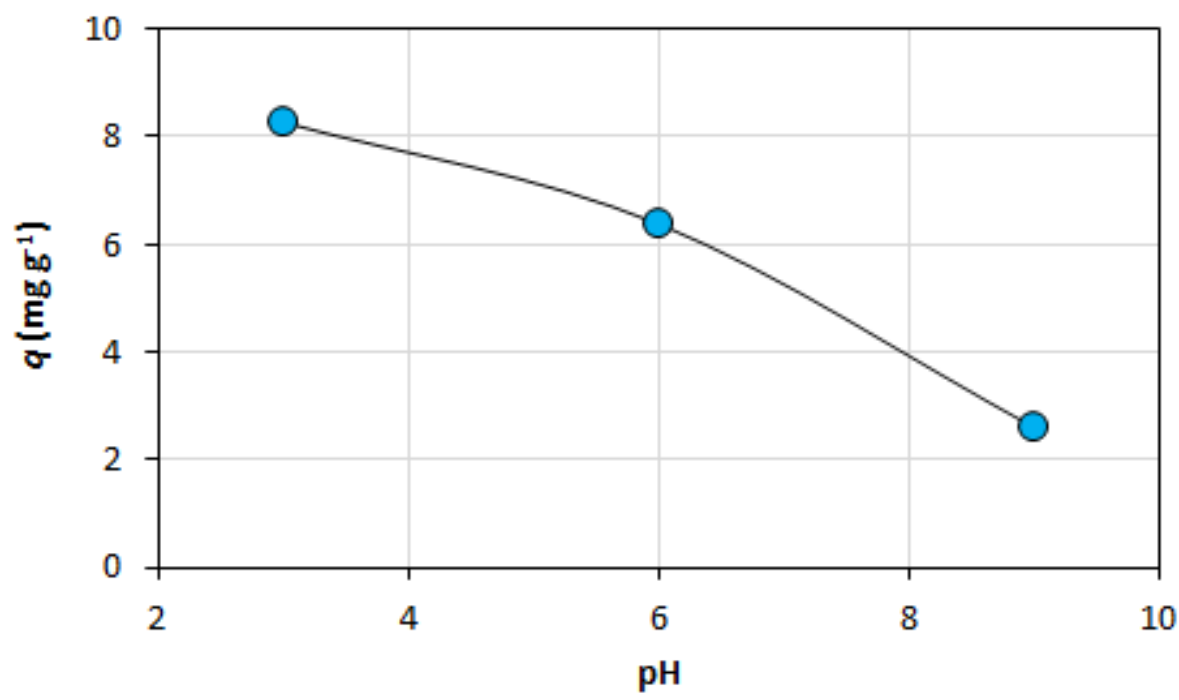

Fig. 2. Effect of $\mathrm{pH}$

\subsection{Effect of dye concentration}

As seen in Fig. 3, the dye removal potential of biosorbent increased with increasing concentration of dye. This is because the higher dye concentration provides a greater driving force to overcome the mass transfer resistance of dye molecules between the biosorption medium and biosorbent [6].

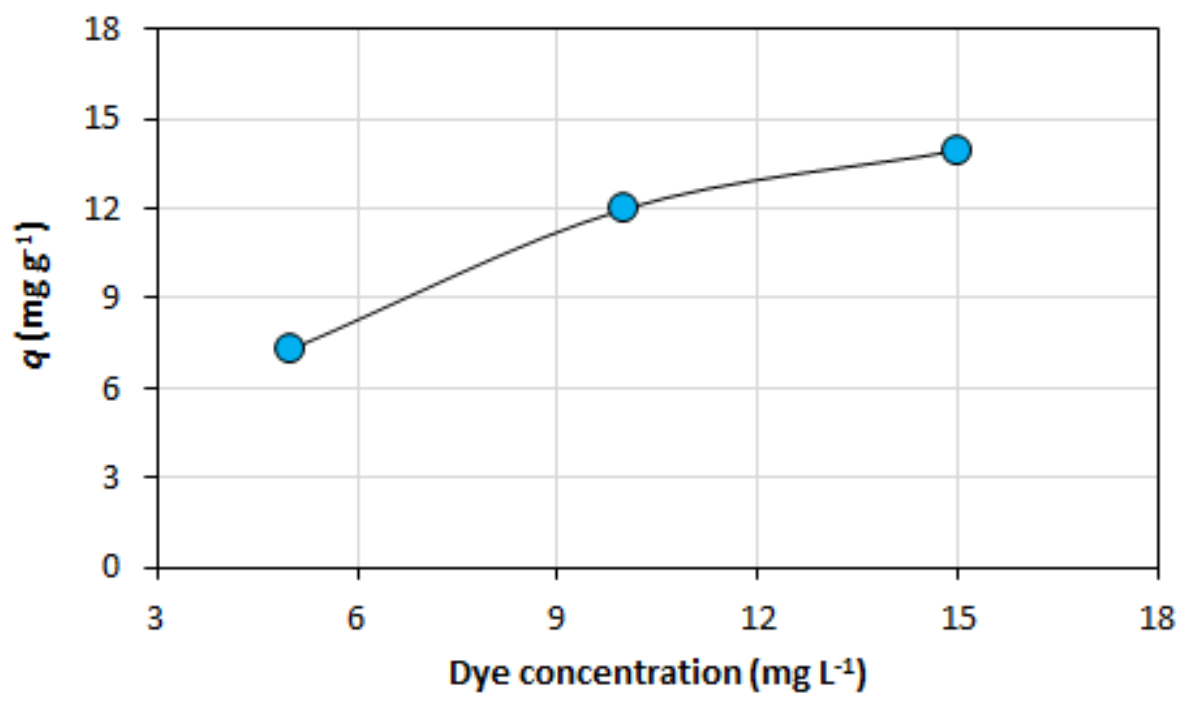

Fig. 3. Effect of dye concentration

\subsection{Effect of biosorbent amount}

The dye biosorption yield of biosorbent material as a function of its amount is demonstrated in Fig. 
4. The biosorption capacity decreased with increasing amount of biosorbent. The reduction in the dye removal potential of biosorbent could be attributed to the unsaturation of biosorption sites and/or the particle aggregation of biosorbent $[1,7]$.

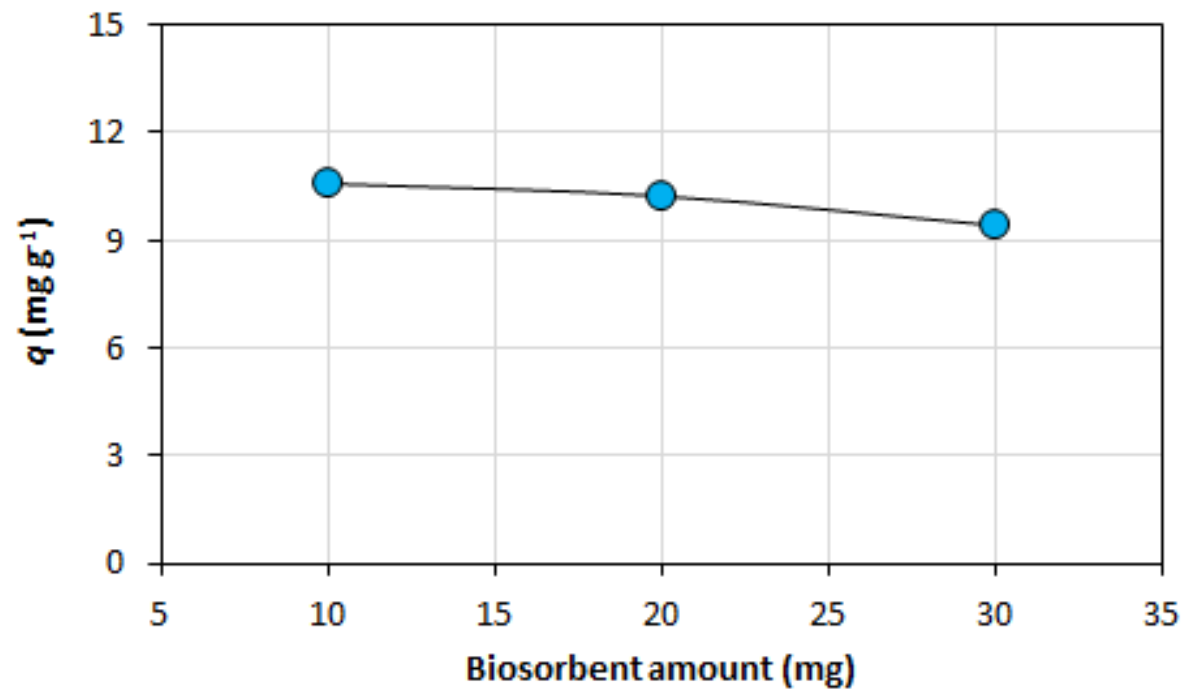

Fig. 4. Effect of biosorbent amount

\subsection{System modeling studies}

The pseudo-first-order [8], pseudo-second-order [9], Elovich [10] and intra-particle diffusion [11] kinetic models were employed for the modeling of dynamic behavior of biosorption system and the parameters of these models and statistical data are presented in Table 1. Considering its high $R^{2}$ value and also low SE value, Elovich model provided the best fit to the experimental data of dye biosorption. This model suggests that the biosorption of dye occurs on the heterogeneous surface active sites of biosorbent $[3,12]$. The intra-particle mass transfer model showed that the biosorption process might be governed by multi-step mechanisms [4, 13]. 
Table 1. Biosorption kinetic modeling data

\begin{tabular}{ccc}
\hline Model & Parameter & Value \\
\hline Pseudo-first-order & $q_{\mathrm{e}}\left(\mathrm{mg} \mathrm{g}^{-1}\right)$ & 14.633 \\
& $k_{1}\left(\mathrm{~min}^{-1}\right)$ & 0.044 \\
& $R^{2}$ & 0.9090 \\
& $\mathrm{SE}$ & 1.636 \\
\hline Pseudo-second-order & $q_{\mathrm{e}}\left(\mathrm{mg} \mathrm{g}^{-1}\right)$ & 15.695 \\
& $k_{2}\left(\mathrm{~g} \mathrm{mg}^{-1} \mathrm{~min}^{-1}\right)$ & 0.004572 \\
& $R^{2}$ & 0.9623 \\
& $\left.\mathrm{SE}^{-1} \mathrm{~min}^{-1}\right)$ & 1.054 \\
\hline Elovich & $\alpha\left(\mathrm{mg} \mathrm{g}^{-1} \mathrm{mg}^{-1}\right)$ & 2.422 \\
& $\beta\left(\mathrm{g}^{2}\right.$ & 0.413 \\
& $\mathrm{SE}^{2}$ & 0.9940 \\
& $C\left(\mathrm{mg} \mathrm{g}^{-1}\right)$ & 0.419 \\
\hline Intra-particle diffusion & $k_{\mathrm{p}}\left(\mathrm{mg} \mathrm{g}^{-1} \mathrm{~min}^{-1 / 2}\right)$ & 3.772 \\
& $R^{2}$ & 0.763 \\
& $\mathrm{SE}$ & 0.8764 \\
& & 1.907 \\
\hline
\end{tabular}

The equilibrium data of biosorption process were modeled using the isotherm models of Freundlich [14], Langmuir [15] and Dubinin-Radushkevich [16]. The parameters of these isotherm models are presented in Table 2. According to the statistical evaluation results, Langmuir model showed the best fit to the equilibrium data of dye biosorption. This isotherm model suggests that the biosorption of pollutant takes place on the homogeneous surface of biosorbent and the treatment of pollutant follows a monolayer biosorption process $[12,17]$. The values of $n_{\mathrm{F}}$ lying in the range of 1 and 10 and the values of $R_{\mathrm{L}}$ lying in the range of 0 and 1 indicate that this dye biosorption system is a favorable treatment process $[1,3]$. On the other hand, the mean free energy of biosorption value (E) less than $8 \mathrm{~kJ} \mathrm{~mol}^{-1}$ shows that the biosorption process might be controlled by means of physical mechanisms [18]. 
Table 2. Biosorption isotherm modeling data

\begin{tabular}{ccc}
\hline Model & Parameter & Value \\
\hline Freundlich & $K_{\mathrm{F}}\left(\mathrm{mg} \mathrm{g}^{-1}\left(\mathrm{~L} \mathrm{mg}^{-1}\right)^{1 / n} \mathrm{~F}\right)$ & 4.030 \\
& $n_{\mathrm{F}}(-)$ & 1.859 \\
& $R^{2}$ & 0.9688 \\
& $\mathrm{SE}$ & 0.986 \\
\hline Langmuir & $q_{\mathrm{m}}\left(\mathrm{mg} \mathrm{g}^{-1}\right)$ & 26.834 \\
& $K_{\mathrm{L}}\left(\mathrm{L} \mathrm{mg}^{-1}\right)$ & 0.112 \\
& $R_{\mathrm{L}}(-)$ & 0.373 \\
$R^{2}$ & 0.9936 \\
& $\mathrm{SE}$ & 0.447 \\
\hline Dubinin-Radushkevich & $q_{\mathrm{m}}\left(\mathrm{mg} \mathrm{g}^{-1}\right)$ & 16.884 \\
& $E\left(\mathrm{~kJ} \mathrm{~mol}^{-1}\right)$ & 0.440 \\
$R^{2}$ & 0.9893 \\
& $\mathrm{SE}$ & 0.577 \\
\hline
\end{tabular}

\section{Conclusion}

The sawdust waste biomass was explored as a sustainable alternative biosorbent source for the treatment of colored aqueous effluents. The operating conditions significantly affected the biosorption process. Elovich and Langmuir models provided the best fit to the kinetic and isotherm data, respectively. The maximum dye biosorption capacity of biosorbent was found to be 26.834 $\mathrm{mg} \mathrm{g}^{-1}$. The obtained findings showed that this forest industry waste biomass could be employed as an eco-friendly biosorbent material for the synthetic dye bioremediation.

\section{References}

[1] Rangabhashiyam S, Sujata L, Balasubramanian P. Biosorption characteristics of methylene blue and malachite green from simulated wastewater onto Carica papaya wood biosorbent. Surf Interfaces. 2018; 10: 197-215.

[2] Santos SCR, Boaventura RAR. Adsorption of cationic and anionic azo dyes on sepiolite clay: Equilibrium and kinetic studies in batch mode. J Environ Chem Eng. 2016; 4: 1473-1483.

[3] Reck IM, Paixão RM, Bergamasco R, Vieira MF, Vieira AMS. Removal of tartrazine from aqueous solutions using adsorbents based on activated carbon and Moringa oleifera seeds. J Clean Prod. 2018; 171: 85-97.

[4] Li C, Wang X, Meng D, Zhou L. Facile synthesis of low-cost magnetic biosorbent from peach gum polysaccharide for selective and efficient removal of cationic dyes. Int J Biol Macromol. 2018; 107: 18711878.

[5] Konicki W, Hełminiak A, Arabczyk W, Mijowska E. Adsorption of cationic dyes onto Fe@graphite core-shell magnetic nanocomposite: Equilibrium, kinetics and thermodynamics. Chem Eng Res Des. 2018; 129: 259-270.

[6] Nayak AK, Pal A. Green and efficient biosorptive removal of methylene blue by Abelmoschus esculentus seed: Process optimization and multi-variate modeling. J Environ Manage. 2017; 200: 145-159. [7] dos Santos A, Viante MF, Pochapski DJ, Downs AJ, Almeida CAP. Enhanced removal of p-nitrophenol from aqueous media by montmorillonite clay modified with a cationic surfactant. J Hazard Mater. 2018; 355: 136-144. 
[8] Lagergren S. About the theory of so-called adsorption of soluble substances. K Sven Vetenskapsakad Handl. 1898; 24: 1-39.

[9] Ho YS. Review of second-order models for adsorption systems. J Hazard Mater. 2006; 136: 681-689. [10] Chien S, Clayton W. Application of Elovich equation to the kinetics of phosphate release and sorption in soils. Soil Sci Soc Am J. 1980; 44: 265-268.

[11] Weber WJ, Morris JC. Kinetics of adsorption on carbon from solution. J Sanit Eng Div Am Soc Civ Eng. 1963; 89: 31-60.

[12] Mokhtar N, Aziz EA, Aris A, Ishak WFW, Mohd Ali NS. Biosorption of azo-dye using marine macroalga of Euchema spinosum. J Environ Chem Eng. 2017; 5: 5721-5731.

[13] Albadarin AB, Solomon S, Daher MA, Walker G. Efficient removal of anionic and cationic dyes from aqueous systems using spent Yerba Mate "Ilex paraguariensis". J Taiwan Inst Chem Eng. 2018; 82: 144155.

[14] Freundlich HMF. Over the adsorption in solution. Z Phys Chem. 1906; 57: 385-470.

[15] Langmuir I. The adsorption of gases on plane surfaces of glass, mica and platinum. J Am Chem Soc. 1918; 40: 1361-1403.

[16] Dubinin MM, Radushkevich LV. Equation of the characteristic curve of activated charcoal. Proc Acad Sci Phys Chem Sec USSR. 1947; 55: 331-333.

[17] Guo H, Bi C, Zeng C, Ma W, Yan L, Li K, et al. Camellia oleifera seed shell carbon as an efficient renewable bio-adsorbent for the adsorption removal of hexavalent chromium and methylene blue from aqueous solution. J Mol Liq. 2018; 249: 629-636.

[18] Agarwal S, Gupta VK, Ghasemi M, Azimi-Amin J. Peganum harmala-L Seeds adsorbent for the rapid removal of noxious brilliant green dyes from aqueous phase. J Mol Liq. 2017; 231: 296-305. 